\title{
A ATUAÇÃO DE COORDENADORES DE CURSO DE UMA UNIVERSIDADE PÚBLICA: INTERFACES DA GESTÃO DO CONHECIMENTO EXPLÍCITO E TÁCITO
}

\author{
Pedro Luís Bilheiro; Alex Sandro Gomes Pessoa \\ Universidade do Oeste Paulista - UNOESTE, Programa de Pós-Graduação em Educação, Presidente Prudente, SP. E- \\ mail: bilheiro@unoeste.br.
}

\begin{abstract}
RESUMO
O objetivo deste artigo foi analisar como os coordenadores de curso de uma universidade pública lidam com suas tarefas administrativas, articulando suas percepções com as discussões sobre a gestão do conhecimento explícito e tácito. A coleta de dados se deu por intermédio da condução de entrevistas semiestruturadas com coordenadores de curso de uma universidade pública e fundamentou-se em discussões sobre gestão do ensino superior e experiências do cargo. Por intermédio da análise de conteúdo, concluímos que mesmo a universidade sendo uma instituição com características tradicionais e burocráticas, diretamente ligadas ao conhecimento formalizado por regras e regulamentos, hierarquia interna e papéis formalizados, canais de comunicação definidos, percebe-se que o conhecimento tácito e o explícito não são entidades separadas, mas mutuamente complementares na empreitada de gestão no ensino superior.
\end{abstract}

PALAVRAS-CHAVE: gestão; universidade, coordenador de curso; conhecimento explícito; conhecimento tácito.

\section{THE ROLE OF COORDINATORS OF UNDERGRADUATE COURSE IN A PUBLIC UNIVERSITY: INTERSECTIONS BETWEEN EXPLICIT AND TACIT KNOWLEDGE}

\begin{abstract}
The objective of this article was to analyze how the coordinators of undergraduate course in a public university deal with their administrative tasks, articulating their perceptions with the discussions about the management of explicit and tacit knowledge. The data gathering was done through semi-structured interviews with coordinators of undergraduate course in a public university and was based on discussions about management of higher education and experiences related to their experiences. Through the analysis of content, we conclude that even the university being an institution with traditional and bureaucratic characteristics, directly linked to the knowledge formalized by rules and norms, as well as internal hierarchy and formalized roles, it is perceived that tacit and explicit knowledge are not separate concepts, but mutually complementary in the management in higher education.
\end{abstract}

KEYWORDS: management; university, course coordinator; explicit knowledge; tacit knowledge. 


\section{INTRODUÇÃO}

Os estudos sobre conhecimento apontam para a existência de dois tipos distintos: o conhecimento explícito e o conhecimento tácito. Ambos são importantes e não podem ser estudados separados, uma vez que fazem parte do movimento da própria estruturação do pensamento e da capacidade criativa do ser humano.

Para Torres (2002), o conhecimento é considerado explícito quando as pessoas podem falar acerca dele, as ideias e os significados que se encontram podem ser memorizados, recuperados, repensados, relacionados e transmitidos de forma escrita. Na mesma direção, Angeloni (2002) pontua que esse tipo de conhecimento é explícito, formal e sistemático, e pode ser facilmente comunicado e partilhado.

Já o conhecimento tácito é altamente pessoal, de difícil formalização e comunicação. O conhecimento considerado tácito é compreendido como subjetivo, prático ou pessoal, quando está intimamente ligado a experiência de vida de cada pessoa. É, portanto, um conhecimento da prática, do cotidiano e que torna mais difícil de registrar, de documentar ou de ensinar aos outros (ANGELONI, 2002).

Para Mundim (2002), tanto o conhecimento explícito quanto o conhecimento tácito podem ter um contexto individual ou organizacional, o que é caracterizado como o conhecimento tácito individual (habilidades e experiências individuais) e o conhecimento coletivo tácito (soma das habilidades individuais). Acrescenta o autor que o conhecimento coletivo tácito é mais difícil de avaliar, devido sua qualidade pessoal, que envolve a percepção e a linguagem das pessoas.

Em uma organização de ensino superior o conhecimento organizacional explícito pode ser entendido como o conhecimento exibido em manuais de procedimentos, resoluções, portarias, memórias de computador, relatórios, pesquisas, entre outros. O conhecimento organizacional tácito é aquele que inclui o discernimento, a percepção e a compreensão profunda dos indivíduos. Sendo assim, partimos da hipótese de que nos modelos de gestão do ensino superior o conhecimento ocorre através da interação entre o conhecimento tácito e explícito. Todavia, a discussão dos conhecimentos tácitos aplicados a esses contextos institucionais é quase inexistente, o que justifica investigações cujo objeto de estudo sejam os conhecimentos produzidos no cotidiano das instituições de ensino superior.

Com base nessas interlocuções teóricas e na constatação da escassez de trabalhos científicos dessa natureza, o objetivo deste artigo foi analisar como os coordenadores de curso de uma universidade pública lidam com suas tarefas administrativas, articulando suas percepções com as discussões sobre a gestão do conhecimento explícito e tácito, na execução de suas tarefas.

\section{METODOLOGIA}

A pesquisa se caracteriza como exploratória e descritiva, fundamentada na abordagem qualitativa.

A pesquisa foi realizada em uma universidade pública, localizada em uma cidade do interior do estado de São Paulo. A instituição tem aproximadamente 3000 (três mil) alunos matriculados nos cursos de graduação. Além disso, conta com a colaboração de cerca de 200 docentes e 230 servidores técnico-administrativos. A unidade funciona distribuída em nove departamentos de ensino e conta atualmente com doze coordenadores de cursos de graduação.

A amostra foi constituída por conveniência, sendo que todos os coordenadores de curso de graduação da unidade universitária foram convidados a participar da pesquisa. O contato foi realizado por e-mail e, no caso de não obtenção de respostas, fizemos o contato por telefone. Porém, tivemos a participação de nove coordenadores de curso, uma vez que alguns justificaram que em virtude da quantidade de compromissos, não poderiam disponibilizar tempo em suas agendas de compromissos diários. 
A coleta de dados se deu através de entrevista semiestruturada. O conteúdo das perguntas foi fundamentado nas discussões sobre a atuação do coordenador em suas atividades e procedimentos usados para a gestão do curso, além das dificuldades rotineiras e suas motivações para exercer o cargo. Nesse sentido, as questões buscaram identificar a percepção dos coordenadores de curso sobre os procedimentos estabelecidos formalmente (em legislações, manuais, normas, entre outros) e que contribuem para o desenvolvimento de suas atividades, ou seja, o conhecimento explícito. A segunda parte do roteiro abordou os procedimentos não registrados oficialmente, portanto, criados pelos próprios coordenadores de curso frente às necessidades e desafios que surgem na sua rotina de trabalho, reiterando nosso interesse pela compreensão do conhecimento tácito.

Apresentamos o projeto de pesquisa ao Comitê de Ética em Pesquisa com Seres Humanos (CEP) da Universidade do Oeste Paulista, o qual foi aprovado (CAAE: 57167716.7.0000.5515). O contato com os coordenadores de curso da universidade foi feito para explicar os procedimentos da pesquisa e solicitar o aceite deles. As entrevistas ocorreram na própria instituição de ensino superior, ou seja, no local de trabalho dos entrevistados. O contato foi individual e utilizamos um gravador digital para registro das falas que emergiram nesse contato. As entrevistas duraram um tempo médio de quinze minutos.

Para a análise do material foi utilizada a técnica de análise de conteúdo, proposta por Bardin (2012). A transcrição manteve o anonimato dos entrevistados, ou seja, foram criados pseudônimos para garantir a liberdade de expressão e maior confiabilidade das informações prestadas pelos participantes. Na última etapa da pesquisa foi feita a análise e interpretação dos dados de acordo com os objetivos previstos.

\section{RESULTADOS}

Nas entrevistas foram verbalizadas situações de aplicação do conhecimento tácito em suas rotinas de trabalho, como possibilidade de desenvolver e melhorar suas atividades diárias. Mesmo sendo a universidade uma instituição com características tradicionais e burocráticas, diretamente ligadas ao conhecimento formalizado por regras e regulamentos, hierarquia interna, papéis formalizados, canais de comunicação definidos, percebe-se que o conhecimento tácito e o explícito não são entidades separadas, mas mutuamente complementares que interagem um com o outro e realizam trocas nas atividades criativas dos seres humanos, fazendo com que o desempenho das organizações seja também o resultado da combinação dos conhecimentos tácitos e explícitos dos indivíduos ("a gente acaba modificando várias Resoluções, as ACC, as resoluções dos TGs numa maneira de formalizar coisas que a gente acaba tendo que fazer pelo bom senso, mas que fica um bom senso igual pra todos e justificado no papel que nos temos um respaldo legal inclusive" - C5).

Também foi citado o "Manual da Graduação" da universidade, como forma de ajuda na tomada de decisões ("O manual de graduação né (risos) é o que ajuda um pouco a gente. $E$ quando a gente não conhece ai vai atrás né dessas legislações. São tantas leis, tantas coisas que quando a gente vê o problema corre atrás. Mas uma coisa que eu consulto é o manual de graduação" - C6). Porém, foi enfatizado que são muito numerosas as legislações vigentes e que as tarefas do dia a dia, bem como as diversas responsabilidades docentes e de coordenação dificultam o trabalho. Diante disso, fazem-se necessários momentos de formação com os coordenadores, tendo em vista que nestes espaços poderão ser discutidas problemáticas, dúvidas e inovações para o trabalho.

Em relação à tomada de decisões, a maior parte dos coordenadores afirma recorrer ao Conselho de Curso, que é composto pelo coordenador, vice-coordenador, quatro representantes docentes que atuam no curso e por dois representantes discentes do curso ("todos os procedimentos e ações que eu vou tomando no curso, eu tenho tomado o cuidado de não agir por 
impulso. Quando aparece alguma coisa a gente busca na legislação, se não tem, eu trago pro conselho e a gente discute aqui" - C7). Esse Conselho tem um mandato de dois anos, com exceção dos representantes discentes que é de um ano. Ocorre, em média, uma reunião ordinária por mês, sendo que podem ser convocadas reuniões extraordinárias se houver necessidade de deliberar sobre algum assunto urgente.

Os coordenadores entrevistados também relataram que muitas vezes tomam decisões procurando a opinião de ex-coordenadores e/ou docentes mais antigos do curso, conforme relatos abaixo ("As dúvidas (relacionadas à legislação) que eu tenho eu procuro buscando de outros... de pessoas mais velhas ou a coordenação ou da graduação" - C1).

A frente desse Conselho de Curso, o coordenador, segundo Marquesin, Penteado e Baptista (2008), muitas vezes pode se deparar com decisões coletivas possam gerar conflitos, embora fortaleçam ainda mais o grupo, por possibilitar discussões que permitem o enriquecimento da prática pedagógica. Assim sendo, mesmo diante de algumas discussões em reuniões entre os membros do conselho de curso, acreditamos que elas podem ser positivas, visto que fortalecem ainda mais o coletivo, bem como acrescentam o aprendizado dos envolvidos.

\section{DISCUSSÃO}

Acreditamos, com base nas entrevistas conduzidas, que os conhecimentos tácitos e explícitos possuem influência direta nessas discussões e comportamentos, pois a posição que se defende, a ideia que se tem de determinado assunto, é algo que o ser humano ou adquire em estudos e pesquisas realizadas ou mesmo das experiências ao longo da vida. Este "saber" negligenciado em outros tempos passa agora a ocupar o centro de várias discussões. Para Nonaka e Takeuchi (2008) o conhecimento tácito está intimamente ligado à experiência de vida de cada pessoa, diferente do conhecimento explícito que é teórico e impessoal, adquirido em espaços de formação geralmente institucionalizadas.

Foram verbalizadas pelos entrevistados várias situações de aplicação do conhecimento tácito em suas rotinas de trabalho, como possibilidade de desenvolver e melhorar suas atividades diárias. Mesmo sendo a universidade uma instituição com características tradicionais e burocráticas, diretamente ligadas ao conhecimento formalizado por regras e regulamentos, hierarquia interna, papéis formalizados, canais de comunicação definidos, percebe-se que o conhecimento tácito e o explícito não são entidades separadas, mas mutuamente complementares que interagem um com o outro e realizam trocas nas atividades criativas dos seres humanos, fazendo com que o desempenho das organizações seja também o resultado da combinação dos conhecimentos tácitos e explícitos dos indivíduos.

Não menos importante é a construção de informações confiáveis, em que cada coordenador possa avaliar as consequências de seus atos e os resultados da ação coletiva. Assim, conforme Desiderio e Ferreira (2004, p.7) "uma participação efetiva pressupõe um compartilhamento da gestão em seus múltiplos aspectos, tais como levantamento de problemas, busca de soluções e comprometimento com a escolha feita".

Desse modo, em concordância com os autores supracitados, acreditamos que a gestão só será compartilhada, isto é, só terá o apoio e colaboração de todos na medida em que seus envolvidos tiverem o conhecimento da sua importância. $E$, isto só poderá ser compreendido por meio de vivências no campo e/ou de estudos na área, ou seja, dos conhecimentos tácitos e explícitos adquiridos ao longo da vida.

\section{CONCLUSÃO}

As experiências e vivências dos coordenadores podem e devem influenciar no seu trabalho, ou seja, seu conhecimento tácito adquirido ao longo de sua vida. De forma similar, os estudos, 
pesquisas feitas e participação em espaços de formação continuada vão contribuir para o desenvolvimento e formação desse profissional.

Mediante uma postura crítica e questionadora, usando de suas experiências de vida (conhecimento tácito), o coordenador pode interferir e orientar a organização do trabalho pedagógico que não pode ser totalmente descrito e/ou prescrito (conhecimento explícito). Dessa forma, a gestão da universidade pública não é uma tarefa fácil, podendo ser considerada até mesmo como um desafio para os gestores na sua relação com a prática laborativa e de seus participantes.

\section{REFERÊNCIAS}

ANGELONI, M. T. Organizações do conhecimento: infra-estrutura, pessoas e tecnologias. São Paulo: Saraiva, 2002.

DESIDERIO, M.; FERREIRA, A. P. F. Desafios da gestão universitária. In: SIMPÓSIO DE EXCELÊNCIA EM GESTÃO E TECNOLOGIA, 1., 2004, Resende. Anais... Resende: AEDB, 2004. Disponível em: <http://www.aedb.br/seget/artigos2004.php?pag=GP>. Acesso em: 25 maio 2017.

MARQUESIN, D. F. B.; PENTEADO, A. F.; BAPTISTA, D. C. O coordenador de curso da instituição de Ensino Superior: atribuições e expectativas. Revista de Educação.. v.11, n. 12, p.7-21, 2008.

MUNDIM, A. P. F. Desenvolvimento de produtos e educação corporativa. São Paulo: Atlas, 2002.

NONAKA, I.; TAKEUCHI, H. Gestão do conhecimento. Porto Alegre: Bookman, 2008.

TORRES, P. L. Laboratório on line de aprendizagem: uma proposta crítica de aprendizagem colaborativa para a educação. 2002. 193 f. Tese (Doutorado em Engenharia de Produção) Universidade Federal de Santa Catarina, Florianópolis, 2002.

TOSTA, H. T. et al. Gestores universitários: papel e competências necessárias para o desempenho de suas atividades nas universidades federais. Revista GUAL, Florianópolis, v. 5, n. 2, p. 1-15, ago. 2012. 